\title{
Review \\ Waste Management Strategies to Mitigate the Effects of Fluorinated Greenhouse Gases on Climate Change
}

\author{
Paulo J. Castro ${ }^{1}$, João M. M. Aráujo ${ }^{1}\left(\mathbb{D}\right.$, Graça Martinho $^{2}(\mathbb{D})$ and Ana B. Pereiro ${ }^{1, *(\mathbb{D})}$ \\ 1 LAQV, REQUIMTE, Department of Chemistry, NOVA School of Science and Technology, \\ NOVA University Lisbon, 2829-516 Caparica, Portugal; pj.castro@fct.unl.pt (P.J.C.); \\ jmmda@fct.unl.pt (J.M.M.A.) \\ 2 MARE, Department of Environmental Sciences and Engineering, NOVA School of Science and Technology, \\ NOVA University Lisbon, 2829-516 Caparica, Portugal; mgm@fct.unl.pt \\ * Correspondence: anab@fct.unl.pt; Tel.: +351-212-948-318
}

check for updates

Citation: Castro, P.J.; Aráujo, J.M.M.; Martinho, G.; Pereiro, A.B. Waste Management Strategies to Mitigate the Effects of Fluorinated Greenhouse Gases on Climate Change. Appl. Sci. 2021, 11, 4367. https://doi.org/ 10.3390/app11104367

Academic Editor: Elza Bontempi

Received: 31 March 2021

Accepted: 8 May 2021

Published: 11 May 2021

Publisher's Note: MDPI stays neutral with regard to jurisdictional claims in published maps and institutional affiliations.

Copyright: (c) 2021 by the authors. Licensee MDPI, Basel, Switzerland. This article is an open access article distributed under the terms and conditions of the Creative Commons Attribution (CC BY) license (https:// creativecommons.org/licenses/by/ $4.0 /)$.
Featured Application: This work aims at raising awareness to the need to implement more efficient strategies to manage fluorinated greenhouse gases (F-gases) that are major contributors to global warming and climate change. Only a fraction of these gases is effectively recovered and/or reused, with the remaining being released into the environment. This critical review aims at providing an overview of the strategies currently used to reduce the emissions of F-gases and of the new strategies that are being developed to valorize the existing refrigerants, under circular economy principles.

Abstract: Fluorinated greenhouse gases (F-gases) are used for various applications, such as in refrigeration and air conditioning, as substitutes of the ozone-depleting substances. Their utilization has increased drastically over the last few decades, with serious consequences for global warming. The Kigali Amendment to the Montreal Protocol and several national and international legislations, such as the 2014 EU F-gas Regulation, aim to control the utilization and emissions of these gases. In the EU, the phase-down of hydrofluorocarbons (HFCs) is underway, with successive reductions in quotas up to 2050. Under this scenario, efficient strategies for managing the produced and already existing F-gases are of vital importance to guarantee that their effect on the environment is mitigated. Up to now, most of the F-gases recovered from end-of-life equipment or when retrofitting systems are either released into the atmosphere or destroyed. However, in order to put forward a cost-efficient adaptation to the F-gas phase-down, increasing separation and recycling efforts must be made. This critical review aims at providing a revision of the current F-gas management problems and strategies and providing an overview on the innovative strategies that can be applied to contribute to build a sustainable market under circular economy principles.

Keywords: fluorinated greenhouse gases; gas separation; WEEE; refrigerant reclamation; refrigerant recycling; climate change; circular economy

\section{Introduction}

Since the 19th century, several gases with different chemical and physical properties have been investigated for refrigeration and other industrial applications. From the first toxic and flammable compounds, great advances have been made until the development of the refrigerants used nowadays. In the 20th century, chlorofluorocarbons (CFCs) gained great popularity due to their non-toxicity, non-flammability, and high efficiency, and therefore their atmospheric concentrations increased drastically. However, it was found that these compounds are not harmless and destroy the ozone layer [1]. In this scenario, compounds lacking chlorine atoms, such as hydrofluorocarbons (HFCs), emerged as substitutes for ozone-depleting compounds [2]. HFCs, together with perfluorocarbons 
(PFCs), sulfur hexafluoride $\left(\mathrm{SF}_{6}\right)$, and nitrogen trifluoride $\left(\mathrm{NF}_{3}\right)$, are the so-called fluorinated greenhouse gases (F-gases). These synthetic gases have several advantages over naturally occurring gases, such as durability, inertness, non-flammability, non-explosivity, non-reactivity, non-toxicity, and thermal stability [3]. While these properties are ideal for refrigeration and other industrial applications, these compounds are harmful to the environment. Most F-gases are highly stable in the atmosphere, with an atmospheric lifetime of up to 50,000 years, and are potent greenhouse gases (GHGs), with a global warming potential (GWP) up to 23,000 times greater than that of $\mathrm{CO}_{2}$. Consequently, small atmospheric concentrations of F-gases induce large effects on global temperature and have a great impact on climate change. Upon releasing, F-gases persist in the atmosphere and their effects cannot be controlled, affecting the environment for long periods. Therefore, the substitution of F-gases by other compounds is essential to control their impacts in the environment.

In 2015, F-gases represented 2\% of the global GHG emissions [4], and in 2018 they were $3 \%$ of the GHG emissions in the EU [5]. Considering the high GWP of the F-gases, they have a major contribution to global warming. While the emissions of all other GHGs in the EU have decreased, the emissions of F-gases almost doubled from 1990 to 2014 [5] and were expected to have a 4 to 5-fold increase in 2005-2050 if efficient measures were not taken [6].

A key aspect of F-gases is that they are synthetic. Therefore, unlike natural pollutants, their production, use, and emissions can be almost totally controlled if appropriate and efficient legislations and practices are applied. The transition into alternatives with lower GWP is already underway and it is expected that it can be achieved almost totally in the near future. However, most of the F-gases produced in the last few decades are stored inside equipment or are part of several products. Therefore, the correct handling and management of these equipment and products, even after the complete transition of the new alternatives, is key to control the release of F-gases into the atmosphere.

This critical review aims at giving a perspective of the legislation and mechanism to progress the F-gas phase-down and of the current F-gas management practices of waste electrical and electronic equipment (WEEE) and end-of-life vehicles (ELVs). Moreover, it aims at providing insights into new strategies to put forward a cost-efficient adaptation to the F-gas phase-down, based on an improved WEEE and ELV management, with increasing recycling efforts to contribute to a sustainable market under circular economy principles.

\subsection{Applications}

F-gases are widely used for several industrial and commercial applications, mainly as refrigerants in cooling systems, as blowing agents in the manufacturing of organic and inorganic foams and materials, in the manufacturing of electronics, and as part of aerosols, fire extinguishers, and solvents. The most important HFCs used today include the HFC R-134a (GWP 1430) and the HFC blends R-404A (GWP 3922) and R-410A (GWP 2088) [7]. R-404A (GWP 3922) is a blend of R-125 (GWP 3170), R-134a (GWP 1430) and R-143a (GWP 4800), and R-410A (GWP 2088) is a blend of R-32 (GWP 677) and R-125 (GWP 3170).

Almost half of F-gas emissions and about $86 \%$ of the HFC consumption (in GWP) are due to cooling and refrigeration systems [8]. The dependence on these systems, and therefore on F-gases, is increasing worldwide since societies depend largely on: (i) industrial and commercial refrigeration for the functioning of food, chemical, pharmaceutical and other industries, and of the retail sector (for example, supermarkets and restaurants); (ii) domestic refrigerators and freezers in houses and offices; (iii) refrigerator containers for transport; and (iv) stationary and mobile air conditioning to cool personal and commercial transportation vehicles, houses, offices and other buildings. Most systems rely on high GWP F-gases, such as the CFC R-12 (GWP 10,200), the HFC R-134a (GWP 1430), and the HFC blends R-404A (GWP 3922) and R-507A (GWP 3985), and have high leakage rates [9]. These direct emissions of GHGs, together with the high electricity demands (almost 17\% of 
global electricity use) that represent indirect GHG emissions, are responsible for making the cooling and refrigeration sector one of the main contributors to global warming [9].

Today, almost 4 billion pieces of cooling equipment are estimated to be in use globally. This number may rise up to 14 billion by 2050 as a consequence of the rise in global temperatures and of the increasing capacity of the populations in developing countries to have access to cooling equipment [9]. The global energy demand for building cooling more than tripled between 1990 and 2016 and the installed capacity is predicted to rise from $11,670 \mathrm{GW}$ in 2016 to over 36,500 GW in 2050 [9]. Without the international agreements and the application of legislation at international and national levels, the direct and indirect emissions from the air conditioning and refrigeration sectors are projected to rise at least $90 \%$ from 2017 levels by 2050 [9,10]. The increased utilization of F-gases for cooling leads to global warming, creating a feedback loop with dangerous consequences.

Buildings last for several decades and therefore changes in the climate (i.e., increase in temperature and changes in other factors such as wind, solar radiation, and humidity) greatly influence their energy profile over the years. Several studies have addressed the impact of climate change on buildings' energy use, using different methods and climate models [11-16]. While the impacts will be different according to the geographic location, for all regions a decrease in energy use for heating and an increase in energy use for cooling are expected. Since the dependence on refrigeration and cooling will continue to increase in the foreseeable future, it is vital to switch to low GWP refrigerants.

In emergent economies, the increasing demand for air conditioning systems is not being accompanied by the utilization of environmentally friendly alternatives, and high GWP and ozone-depleting refrigerants, such as R-22 (GWP 1760), still dominate the markets [17]. In the markets where R-22 (GWP 1760) is being phased out, the high GWP R-410A (GWP 2088) is the most used refrigerant [17]. The refrigerant R-410A (GWP 2088) is currently being phased out under the current EU legislation, as will be discussed in Section 2 (HFC Phase Down), and the transition to new more environmentally friendly alternatives is taking place.

The market of the air conditioning systems in cars and other transportation vehicles is expanding largely. Despite containing smaller amounts of refrigerant in comparison to other refrigeration and cooling equipment, the leakage rates of mobile air conditioning systems are much higher [3]. Most equipment uses R-134a (GWP 1430), which was adopted worldwide as a substitute to the CFC R-12 (GWP 10,200), and a transition to the low GWP unsaturated HFC R-1234yf (GWP 4) is being put forward [17]. However, the high leakage rates, the inadequate refrigerant handling during maintenance, and improper disposal or release of F-gases from equipment containing high GWP refrigerants still make these equipment major contributors to global warming [3]. In fact, since the treatment of the recovered F-gases has associated costs, the illegal release of the F-gases from end-of-life (EoL) equipment is, in most cases, chosen.

Paradoxically, cooling systems, which have been improving the well-being of societies, are endangering them. As has been pointed out in a study focused on evaluating the efficiencies of the existing room air conditioners in developed countries and in emerging markets, there are still many improvements to make in this sector [17]. In this way, it is essential to improve the energy efficiency of the equipment during the transition to low GWP refrigerants, and to reduce energy consumption, environmental impacts, and costs. Moreover, new technologies and WEEE and ELV management processes must be implemented in the refrigeration and air conditioning sector.

\subsection{Impacts}

The rise in the emissions of F-gases and other GHGs drives global warming and consequently leads to the rise in the sea level and to more frequent and severe floods, droughts, and wildfires. This has severe impacts not only on the health and well-being of populations but also on all earth ecosystems. The impacts of climate change on biodiversity include habitat loss and subsequent invasion of foreign species (including humans), disruptions in 
food chains, and changes in reproduction cycles [18]. Moreover, upon releasing into the atmosphere, F-gases are degraded into harmful by-products, such as hydrogen fluoride (HF) and trifluoroacetic acid (TFA). These compounds can also be generated in destruction facilities upon the incineration of F-gases, and if no appropriate treatment is applied, they are released into the atmosphere. In the atmosphere, both HF and TFA are dissolved in water and are directed to the earth's surface by precipitation, leading to water acidification, and possibly to a significant eco-toxicity upon accumulation in the ecosystems [19]. The drastic climate changes induced by human actions in the last century increased the pressure on the ecosystems to levels impossible to be balanced by natural mechanisms, leading to a biodiversity loss with the fastest rate experienced in the last 65 million years.

HFCs started to be massively used after the implementation of the Montreal Protocol as an alternative to substances that deplete the ozone layer. However, recent studies have demonstrated that despite the indirect effects of HFCs on ozone depletion being small, they are noticeable, considering the great accumulation of these substances in the atmosphere [20]. The increase in the temperature of the troposphere and stratosphere, as a result of the accumulation of HFCs, accelerates the catalytic destruction of ozone. According to that study, HFCs may cause a $0.035 \%$ decrease in the ozone layer by 2015 , with R-125 (GWP 3170) accounting for approximately 50\% of the changes in global temperature and in the ozone levels [20].

HFCs are, therefore, a clear example of a group of substances whose use was promoted with the reasoning of being greener and environmentally friendly, but which revealed unexpected effects, prompting the implementation of new international legislations and seeking new alternatives. While the release of other GHGs may have natural causes, HFCs and other F-gases are synthetic compounds, and their release is strictly related to human actions. In this way, the reduction in the effects of F-gases depends on the establishment of efficient legislation and practices to seek new alternatives and to manage the existing F-gases.

\section{HFC Phase Down}

The impact of F-gases on the health and well-being of societies and on ecosystems is now well recognized by the scientific community, governments, international entities, and the general public. International agreements, with transposition to national legislations, have been signed in the last few decades aiming to establish policy regimes at global and local levels to reduce F-gas emissions and to limit their contribution to climate change.

Initially, the Vienna Convention for the Protection of the Ozone Layer (1985) and the Montreal Protocol (1987) determined the phasing out of ozone-depleting substances, such as chlorofluorocarbons (CFCs). Then, the Kyoto Protocol (1997) and the Paris Agreement (2015) determined the need to limit the atmospheric levels of GHGs at safe values. However, these agreements did not solve the F-gas emission problem. In fact, the phasing out of ozone-depleting substances under the Montreal Protocol and the UE Regulation (EC) No 1005/2009 led to a drastic increase in the utilization of F-gases, such as HFCs, as substitutes for those substances [21]. Then, the Kigali Amendment to the Montreal Protocol, covered by the United Nations Framework Convention on Climate Change (UNFCCC), was signed in 2016. This amendment, which entered into force on 1 January 2019, established the first international regulation to decrease F-gas emissions and replace them by more environmentally friendly alternative refrigerants, aiming at avoiding up to a $0.5^{\circ} \mathrm{C}$ increase in global temperature by the end of the century [22].

The European Union imposed strong F-gas regulations to achieve the goals of the Paris Agreement and of the Kigali Amendment, and the EU's objectives included limiting the rise in the temperature due to climate change at $2{ }^{\circ} \mathrm{C}$ and cutting the overall GHG emissions by $20 \%$ in 2020 , by at least $55 \%$ in 2030 , and up to $95 \%$ in 2050 , compared to 1990 levels [23]. The first EU F-gas Regulation (Regulation (EC) No 842/2006) established measures to improve the management and recovery of F-gases and to restrict the use and marketing of F-gases in cases in which more environmentally friendly and cost-effective 
alternatives exist [24]. This regulation was replaced by the Regulation (EC) No 517/2014, which enforced new mechanisms to ensure an effective reduction in HFC consumption by $79 \%$ and the F-gas emissions by two thirds of the average of 2009-2012 levels by 2030 [23]. This regulation establishes the phase-down of F-gases, bans the use of F-gases in new equipment for which alternative gases are available, establishes annual quotas of produced and imported HFCs, regulates the equipment maintenance to prevent leaks, and regulates the recovery, reclaim or destruction of F-gases at EoL equipment [23]. On one hand, the EU HFC phase-down is defined on carbon dioxide equivalents $\left(\mathrm{CO}_{2} \mathrm{eq}\right)$ and therefore it has a greater impact on high GWP refrigerants, such as R-404A (GWP 3922), R-410A (GWP 2088), R-407A (GWP 2107), and R-134a (GWP 1430) [23]. On the other hand, it does not apply to new alternatives such as unsaturated HFCs, which are only subjected to reporting obligations [23]. This instigated industries to make the transition into refrigerants with a lower GWP (using, for example, unsaturated HFCs, as discussed in Section 2.1).

The European Commission allocates quotas in tonnes $\left(\mathrm{CO}_{2} \mathrm{eq}\right)$ to importers and producers of bulk gases and mandates the registry of HFCs for all companies covered by the quota system, including gas importers and producers and equipment importers. According to EU data, the demand for HFCs has been decreasing since the EU F-gas Regulation was implemented, as a consequence of the increased demand for low-GWP alternatives. In 2019, total HFCs placed in the market were $2 \%$ below the quota limit for that year and the amount of reserve quotas is increasing each year [25]. Total imports of F-gases have decreased from 2017, as in 2019 the amounts were $20 \%$ (or 39\% as $\mathrm{CO}_{2} \mathrm{eq}$ ) below those of 2017 (Figure 1). Imports of HFCs fell by about 30\% since 2017, while imports of unsaturated compounds increased by $40 \%$ (Figure 1) [25].

However, as a response to the reductions in the quotas and to the rise in the price of HFCs, the illegal market is thriving. The first reports of the illegal trade of HFCs go back to 2016, and according to the Environmental Investigation Agency (EIA), there is a considerable amount of HFCs that are not included in the quotas but are entering the EU, with the amounts increasing every year [26]. According to the EIA Report publish in April 2019, in many EU member states the amount of imported HFCs is substantially higher than what is reported by the companies. Great discrepancies were reported between custom import data in the EU and custom export data in China. The most pronounced data were related to the import in Denmark, Greece, Lithuania, Croatia, Luxembourg, Latvia, and Malta [26]. According to this report, up to 16 million tons $\left(\mathrm{CO}_{2} \mathrm{eq}\right)$ of HFCs were illegally placed on the market in 2018, which represents around $16 \%$ of the quota for that year [26]. Since in 2021 the HFC quota will be substantially reduced, the EU strategy to reduce the utilization of HFC will be tested. If no mechanisms are implemented to control the illegal trade of HFCs, upon this new reduction in the quotas it will gain even more dominance in the HFC market and will jeopardize the climate objectives of the EU.

\subsection{Reduction in the Dependence on HFCs}

As shown before, the dependence on refrigeration and cooling systems is expected to grow in the foreseeable future. However, considering the dramatic effects of the sector to climate change it is vital to decrease the dependence on high GWP compounds-based systems. For example, the construction of more energy efficient buildings strongly reduces the need for cooling and heating systems, and a more efficient utilization of air conditioning in buildings and vehicles reduces the energy consumption and therefore the indirect emissions of GHGs [27-29]. The reduction in F-gas emissions in the refrigeration and cooling sectors must include innovation and the development of more efficient systems with lower energy consumption, lower amounts of high GWP refrigerants, and lower leakage rates, and also profound changes in the operation and management practices. 

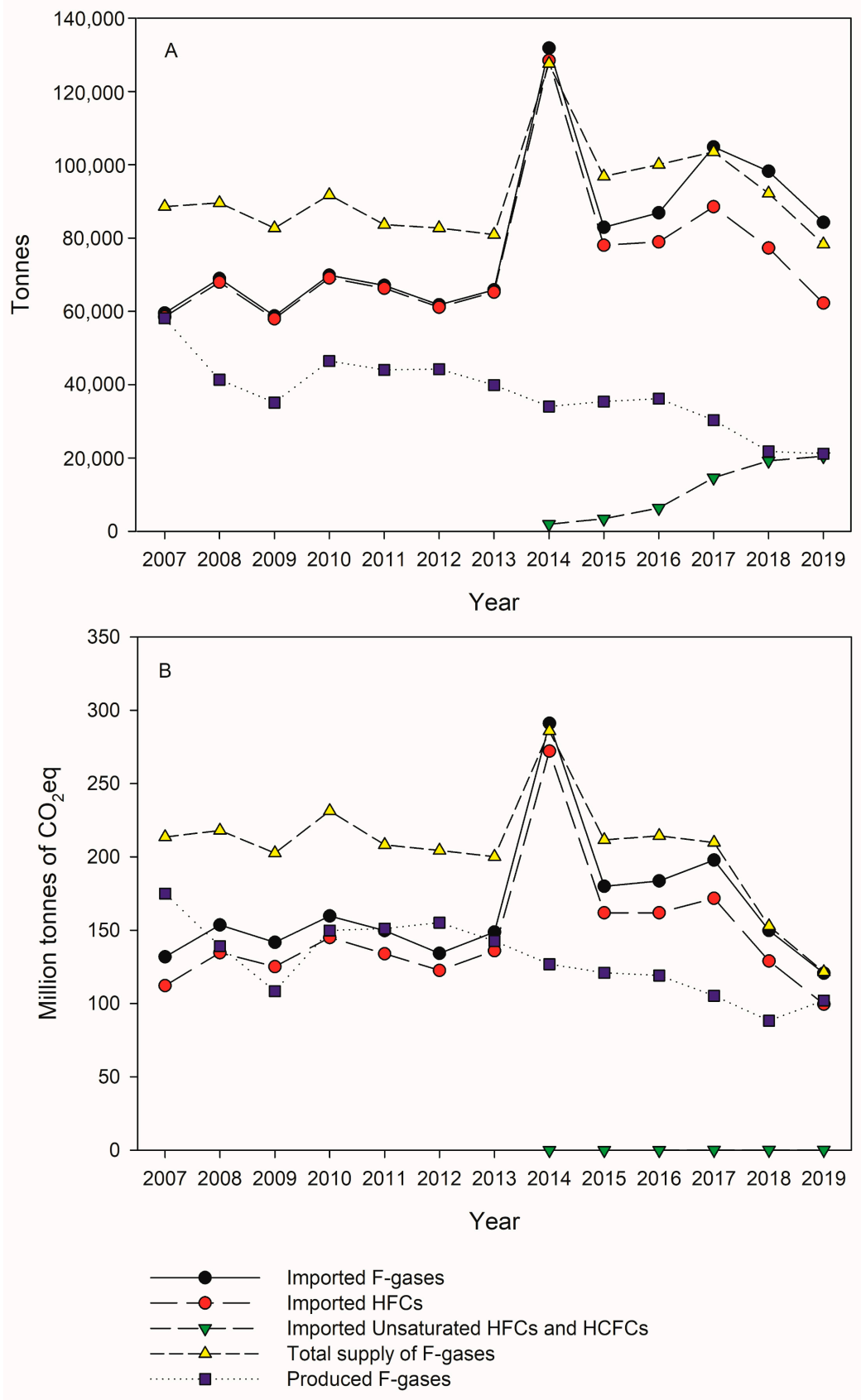

Figure 1. Imports, production and total supply of F-gases and imports of HFCs and of unsaturated HFCs and HCFCs in the EU (2007-2019) according to the EEA Report No 15/2020 on fluorinated greenhouse gases [25]. Data in tonnes of gas (Panel (A)) and in million tonnes of $\mathrm{CO}_{2} \mathrm{eq}(\mathrm{Panel}(\mathbf{B})$ ).

As response to the legislations imposing the HFCs' phase-down, industries quickly developed a new generation of refrigerants with lower GWP, including: (i) natural refrigerants, such as $\mathrm{CO}_{2}$, ammonia and hydrocarbons, which can be efficient but with safety problems; (ii) HFCs with lower GWP, such as R-32 (GWP 677); (iii) unsaturated HFCs, known as hydrofluoroolefins (HFOs); and (iv) blends of these three types of compounds. In many cases, the utilization of non-HFC refrigerants in already existing equipment previously using HFCs is not possible or requires great modifications in the systems. In some cases, the utilization of alternative refrigerants in new equipment requires innovation in the systems, with more robust components and more specialized operation, for example, for using high pressure $\mathrm{CO}_{2}$. 
HFOs, which started to be commercialized in 2010, have no ozone depletion potential and have low GWP, being considered a more environmentally friendly alternative to HFCs for use in cooling, refrigeration and as blowing agents [30]. Due to the high reactivity of their carbon double bonds with radicals in the troposphere, they are rapidly degraded in this zone of the atmosphere [30]. Moreover, most HFOs are chemically stable and inert, nontoxic and have low flammability [20]. The best known unsaturated HFO is 2,3,3,3tetrafluoroprop-1-ene (R-1234yf) with a GWP of 4, which has been developed and proposed for use as a refrigerant in mobile air conditioning in passenger cars as a replacement for HFC-134a [31-33]. Another HFO, R-1234ze (GWP 6), is also being increasingly studied for use as a blowing agent, aerosol propellant, and refrigerant [34]. Some blends of HFCs with HFOs are already replacing HFCs in commercial and industrial refrigeration [32]. Examples of those are R-448A (GWP 1273) (blend of the HFCs R-32 (GWP 677), R-125 (GWP 3170), and R-134a (GWP 1300) with the HFOs R-1234yf (GWP 4) and R-1234ze (GWP 6)), R-449A (GWP 1282) (blend of the HFCs R-32 (GWP 677), R-125 (GWP 3170), and R-134a (GWP 1300) with the HFO R-1234yf (GWP 4)), and R-450A (GWP 605) and R-513A (GWP 573) (blends of the HFC R-134a with the HFOs R-1234ze (GWP 6) and R-1234yf (GWP 4), respectively). The HFO/HFC blends have, in most cases, clear technological advantages. However, since they are new products and are protected by industrial patents, some industrial sectors are reluctant to adopt them due to the additional costs involved.

HFCs with lower GWP, such as R-32 (GWP 677), are currently being used as alternatives to HFC or HFC blends with higher GWP, such as R-410A (GWP 2088) [30]. In some cases, reclamation (i.e., recovering a refrigerant from end-of-life equipment and reprocessing to meet the product specifications for a newly manufactured refrigerant) or the separation and recycling of F-gases from blends for further reuse are valuable alternatives to the destruction of depleted refrigerants aiming at implementing a circular economy and reducing emissions. These approaches will be discussed in the next section (Section 3).

\section{WEEE and ELV Management and Circular Economy}

A multi-way approach to mitigate the effects of F-gases on the climate must include: (i) the phase-down of high GWP compounds and seeking new alternatives; (ii) the improvement of equipment to prevent leaks and the promotion of good handling and operation practices to prevent emissions; and (iii) the efficient management of the produced F-gases, of those recovered from EoL equipment, and of those recovered when retrofitting existing installations. According to the EU F-Gas Regulation, the release of refrigerants into the atmosphere is explicitly prohibited and subjected to penalties. Therefore, refrigerants must be recovered for reuse or destruction [23].

However, much improvement still needs to be achieved globally in the recovery and management of F-gases and other refrigerants. There are two major sources of F-gas residues, WEEE and ELVs, which require different management approaches. Despite having legislation that regulates these procedures and having economic capacity to implement efficient (and sometimes expensive) technologies, developed countries still face challenges to efficiently manage refrigerants. In Portugal, data from 2017 revealed that only $8.7 \%$ of the refrigerants were recovered from equipment and systems and further treated, most probably due to incorrect management by non-certified operators [35]. In developing countries and emerging economies, refrigerant management is even more challenging, mostly due to the lack of efficient legislation, difficulties in implementing technologies, and to the dismantling of equipment to recover metals and other material with no concerns for the potential refrigerant release.

The emission of refrigerants from air conditioning systems in vehicles is challenging due to the high leakage rates in the systems, to the unintentional release of refrigerants due to car accidents, and to the improper recovery and management during the dismantling process. In the EU, the directive 2000/53/EC requires Member States to ensure that EOL vehicles are dismantled and hazardous materials, including HFC refrigerants, are removed [36]. According to Directive 2006/40/EC, from 2017 onward the air conditioning 
systems of all new vehicles cannot contain F-gases with a GWP higher than 150 (e.g., R-134a) [37]. Despite the legislation that determines the switch to lower GWP alternatives in vehicles, the mechanisms to manage the F-gases from EoL equipment present flaws. To reduce the release of F-gases into the atmosphere, they must be recovered from EoL equipment for further destruction or reuse. However, since most workers are not well trained, few incentives are given to the recovery and disposal processes, and to the obligation to pay the costs of disposing, most operators responsible for recovering the refrigerants end up releasing them into the atmosphere. Moreover, a great amount of refrigerant is lost during the system's lifetime. Upon recovery, F-gases can be managed in two main ways. They can be destroyed or they can be reprocessed for further reuse (Figure 2) [38]. The first approach follows a linear economy concept and has the advantage of using already implemented technologies and facilities to achieve an almost complete elimination of the F-gases $[38,39]$. However, emissions of GHGs occur during the transport of the F-gases from the site where they were recovered to the incineration facility and during the incineration process. The second approach follows a circular economy concept and has the advantage of allowing the reuse of value-added refrigerants to reduce the pressure on the supply chain of these compounds, reducing the release of GHGs during the production of new compounds and during their destruction [38]. Moreover, if the reprocessing of the F-gases occurs in the same place where they were recovered, additional benefits in terms of costs and GHG emissions are obtained since the transport (sometimes over long distances) is avoided.

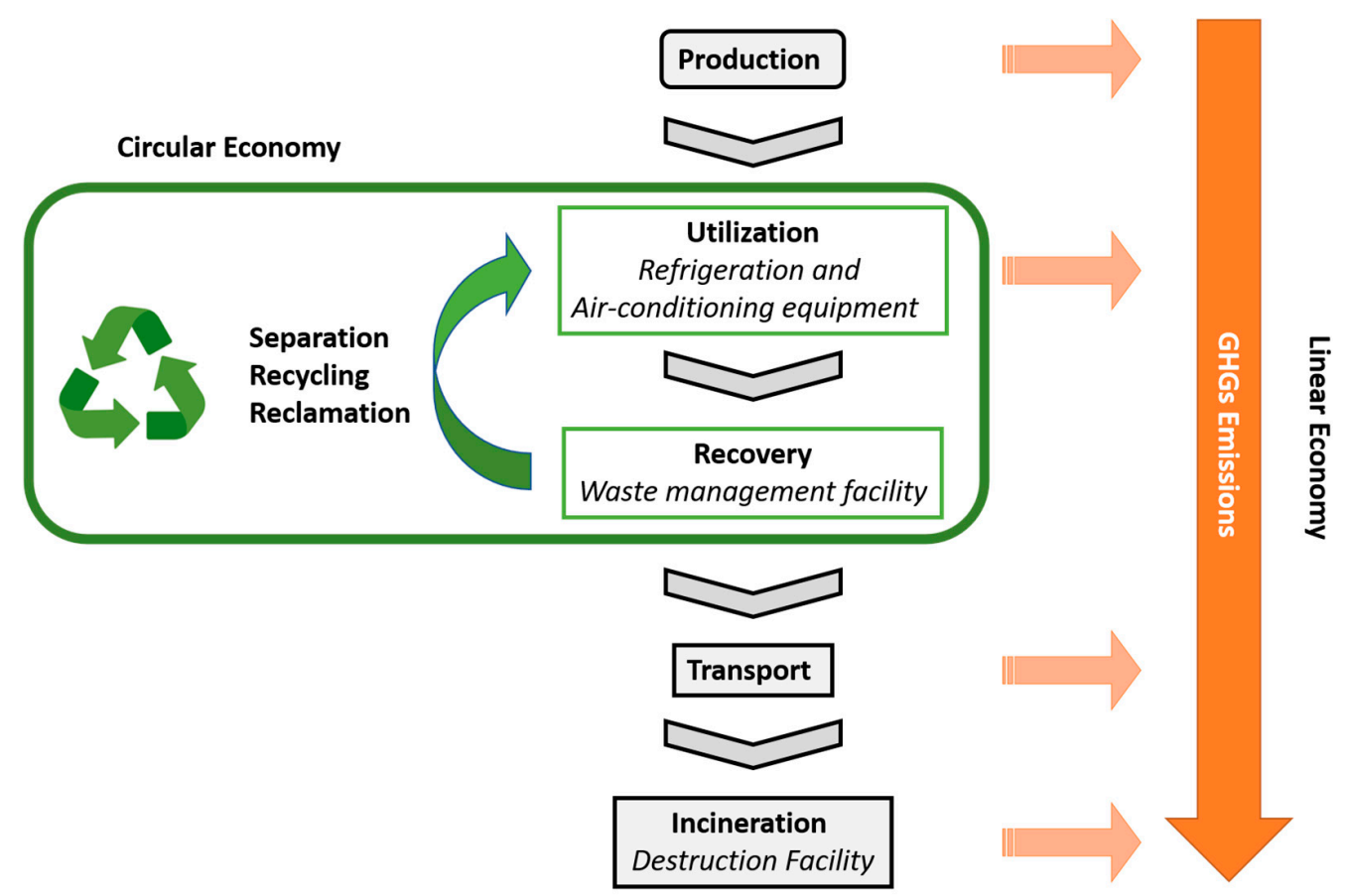

Figure 2. Possible approaches for the management of F-gases, following either a linear economy concept (from production to incineration) or a circular economy concept (involving separation, recycling and/or reclamation processes).

\subsection{Recovery and Destruction}

The destruction of refrigerants, including HFCs and ozone-depleting substances such as CFCs and HCFCs, is considered the best practice for the long-term goal of eliminating these compounds, promoting the switch to more environmentally friendly alternatives. The prohibitions in the use of some HFCs and the phase-down of these compounds only started in the last decade, and therefore little data are available regarding their destruction. This contrasts with ozone-depleting substances, which were prohibited starting in the 1990s and whose destruction is still being performed due to the great amounts of compounds present in equipment and products. In the EU, the reported values of destroyed F-gases 
increased significantly in 2019 compared to 2018 (Figure 3). This increase was of $145 \%$ considering the amount of F-gases (to a total of 1648 tons in 2019) and of $200 \%$ considering the $\mathrm{CO}_{2}$ eq (to a total of 16.6 million tons $\mathrm{CO}_{2}$ eq in 2019) (Figure 3) [25]. Almost the totality of the reported destroyed F-gases in 2019 referred to HFCs. In the same year, 2019, around 1753 tons of CFCs and HCFCs were reported as destroyed in the EU [40].
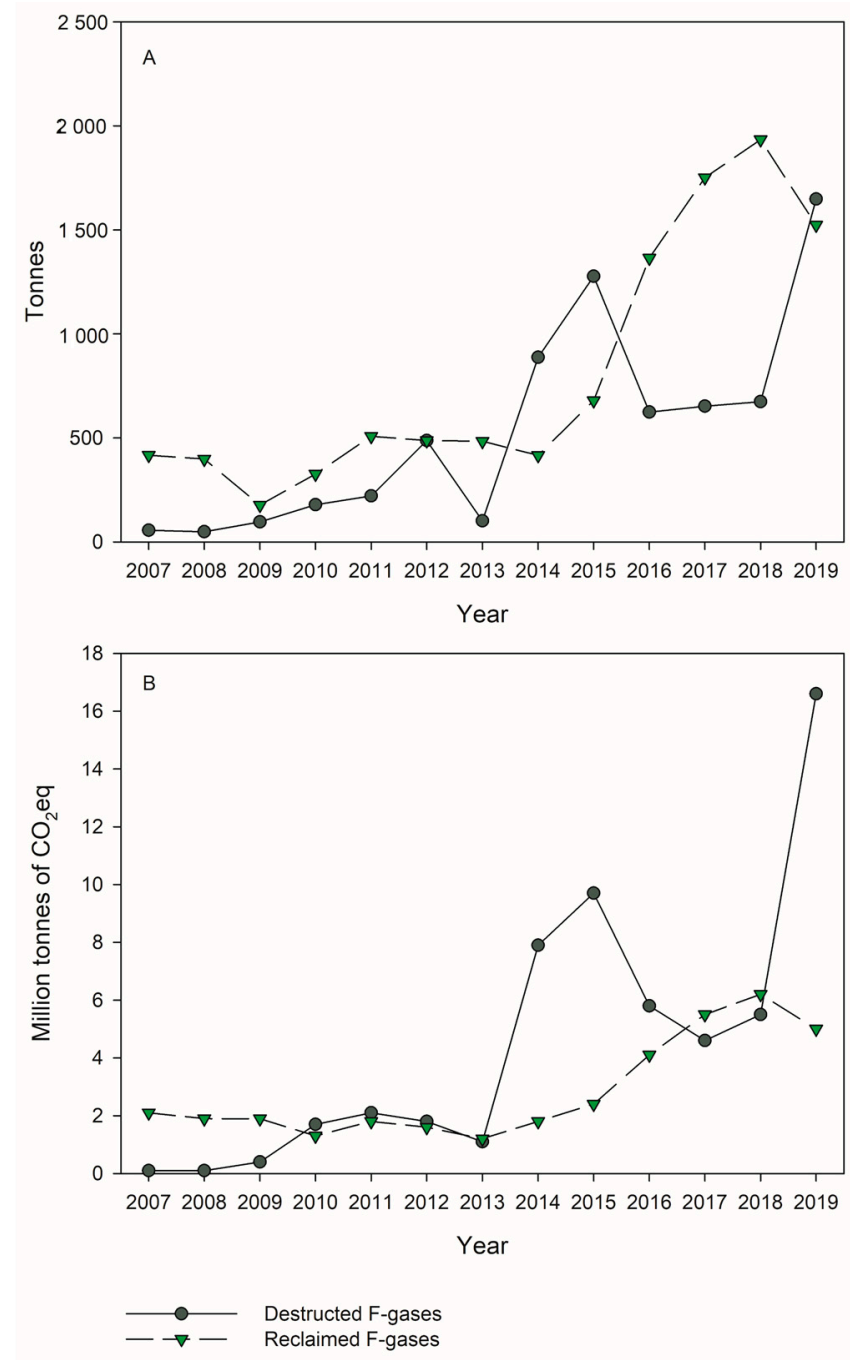

Figure 3. Destruction and Reclamation of F-gases in the EU (2007-2019) according to the EEA Report No 15/2020 on fluorinated greenhouse gases [25]. Data in tonnes of gas (Panel (A)) and in million tonnes of $\mathrm{CO}_{2}$ eq (Panel (B)).

According to an ICF study prepared for the European Commission [29], at least 25 facilities in the EU-27 performed commercial destruction of HFCs and ozone-depleting substances. Fourteen of the identified facilities had an estimated combined destruction capacity of approximately 130,000 tons per year [41]. While some countries have more than one facility (e.g., Germany with eight facilities and Hungary with four facilities), others did not have any facilities at that date (e.g., Portugal and Italy) [41]. The costs for the destruction of HFCs and ozone-depleting substances in the EU have been estimated in the range of EUR 1-EUR 10 per $\mathrm{kg}$ [41]. Since most destruction facilities are located away from the place where the gases are recovered and collected, and in many cases are not even located in the same country, the additional costs of recovery and transportation (estimated to be EUR 0.10 per tonne per kilometer in the EU) must be added [41].

The applicability of current destruction technologies, previously approved for ozonedepleting substances [42], to HFCs has been assessed in 2018 by the UNEP Technology 
and Economic Assessment Panel Task Force on Destruction Technologies [39]. The recommendations include specifications for: (i) a minimum Destruction and Removal Efficiency (DRE) of $99.99 \%$ for concentrated sources or $95 \%$ for dilute sources; (ii) emissions of dioxins and furans, $\mathrm{HCl}$, chlorine, $\mathrm{HF}, \mathrm{HBr}$, bromine, particulate matter, and $\mathrm{CO}$; and (iii) technical capability to be applied at a commercial scale. Since corrosive and harmful products, such as $\mathrm{HF}$ and $\mathrm{HCl}$, are generated during the destruction of HFCs, HCFCs, and CFCs, the systems must be resistant to these compounds and should integrate their neutralization in the process. In many processes, to reduce the generation of those by-products, only small amounts of HFCs and ozone-depleting substances can be treated or are treated together with other compounds.

Three types of technologies that have been used for the destruction of ozone-depleting substances are being used (or being evaluated) for the destruction of HFCs: thermal oxidation (incineration) technologies, plasma technologies, and non-incineration technologies involving chemical transformations [39]. Destruction technologies are expensive, with high initial investments and high operation and energetic costs [39]. Globally, incineration technologies are by far the most used ones due to the lower costs and easiness of implementation (since some facilities are also used to destruct other substances) compared to the other available technologies [39].

\subsubsection{Incineration}

Incineration at temperatures over $1000{ }^{\circ} \mathrm{C}$ has been widely used for the destruction of ozone-depleting substances, such as CFCs and HCFCs. An advantage of incineration is that the generated energy can be harnessed for other processes. It has also been used for the incineration of the HFC R-23 (GWP 12,400), a high GWP compound that is a by-product of the manufacturing of the HCFC R-22 (GWP 1760), which is used as a refrigerant and in blends in foam blowing. Despite being in a phase-out process, the production of R-22 (GWP 1760) has increased, mostly due to its production in developing countries for direct use and due to its worldwide production as a component to make other products. Incineration has been used for the destruction of R-23 (GWP 12,400), but a recent study showed that the atmospheric concentrations of this gas reached very high levels in 2018, beyond what was projected considering the reported R-22 (GWP 1760) production [43]. This suggests that the R-23 (GWP 12,400) incineration facilities, mainly in developing countries, have been deactivated or are not working properly.

The incineration technologies that were developed for the incineration of ozonedepleting substances (either in a dedicated process or in co-incineration with other waste) and of R-23 (GWP 12.400) have been used in some facilities for the degradation of other HFCs. The thermal stability of fluorinated compounds, such as HFCs, has been compared to the one of chlorinated compounds and it was concluded that fluorinated compounds can be destroyed with high efficiency by incineration [44]. The technologies currently in use include cement kilns, liquid injection incineration, municipal solid waste incineration, reactor cracking, and rotary kiln incineration, which have also been used with high potential for the destruction of HFCs, including R-23 (GWP 12,400), R-32 (GWP 677), R-125 (GWP 3170), R-134a (GWP 1300), and R-143a (GWP 4800) [39]. The technologies of gaseous/fume oxidation and porous thermal reactor have been approved for the destruction of HFCs since they were demonstrated to meet the performance criteria established by the UNEP TEAP Task Force on Destruction Technologies [39]. Moreover, alternative methods have been studied at pilot- and full-scale with high efficiency and low emissions. These include a gasification melting system in reductive conditions [45].

Despite being effective for the destruction of HFCs and ozone-depleting substances, incineration processes contribute to global warming due to the release of $\mathrm{CO}_{2}$, and generate harmful by-products. In this way, these processes need to be efficiently designed and operated and tightly controlled to keep emissions at minimum levels. 


\subsubsection{Plasma Technology}

Plasma technologies, based on the destruction of the compounds by the heat generated by a plasma arc, are currently being used to destroy ozone-depleting substances, and HFCs in some cases. The gaseous by-products of these processes include $\mathrm{HCl}, \mathrm{HF}, \mathrm{CO}$, and $\mathrm{CO}_{2}$. These technologies provide high destruction efficiencies, fast decomposition with large throughput, quick start-up and shut-down, greater flexibility of operation and low gas emissions. Moreover, the systems are designed to prevent the formation of dioxins and furans and to neutralize the acids. However, they have high energy consumption.

Different technologies have been developed differing on the methods for producing plasma: by radio frequency, by microwave energy or by an electric plasma torch in the presence of argon or nitrogen. The most widely used technology is the one using argon gas, in facilities operating commercially worldwide. Utilization for the destruction of HFCs and HFC/HCFC blends was reported in Australia, the United States and Mexico. Technology using nitrogen gas was reported for the destruction of R-23 (GWP 12.400) in China and of the HFC R-134a (GWP 1300) and of the HFC blends R-410A (GWP 2088) and R-407C (GWP 1774 ) in Japan. The destruction of R-134 (GWP 1300) using microwave plasma has been investigated and a total conversion degree up to $84 \%$, with no interconversion into other HFCs, was observed [46].

Besides these technologies, others are being investigated and developed specifically for HFCs, aiming to increase efficiency, to improve the flexibility of operation, and to decrease costs of implementation and operation. Such technologies include a water plasma [47] and a dielectric-packed-bed nonthermal plasma reactor with barium titanate beads as the packing material [48], for the decomposition of R-134 (GWP 1300).

\subsubsection{Other Technologies}

The destruction of ozone-depleting substances can also be achieved by converting them into other useful by-products, instead of incinerating them. Different technologies have been approved for the destruction of those substances and have shown potential to also be used for the destruction of HFCs. These technologies include: (i) the conversion by hydration of the compounds into $\mathrm{HF}, \mathrm{HCl}$, and $\mathrm{CO}_{2}$ in a superheated steam reactor whose walls are heated up to $1000{ }^{\circ} \mathrm{C}$, followed by quenching and neutralization of the acids using a $\mathrm{Ca}(\mathrm{OH})_{2}$ solution [39]. This technology, which is being applied in commercial facilities in Japan and China, is safe, easy to operate and has high destruction efficiency and low emissions of pollutants [39]; (ii) the Gas Phase Catalytic Dehalogenation of the compounds at $400{ }^{\circ} \mathrm{C}$ with the neutralization of produced $\mathrm{HCl}$ and $\mathrm{HF}$ in a $\mathrm{Ca}(\mathrm{OH})_{2}$ solution [39]. Japan reported the utilization of this technology to destroy CFCs, HCFCs and HFCs or HFC blends, such as R-134a (GWP 1300), R-245fa (GWP 858), R-404A (GWP 3922), R-407C (GWP 1774), R-407D (GWP 1627), R-407E (GWP 1552), R-410A (GWP 2088), R-417A (GWP 2346), R-507A (GWP 3985) and R-508A (GWP 13,214) [39]; and (iii) the conversion of the compounds into $\mathrm{HF}, \mathrm{HCl}, \mathrm{CO}$, and $\mathrm{H}_{2} \mathrm{O}$ by chemical reaction with $\mathrm{H}_{2}$ and $\mathrm{CO}_{2}$ [39]. The produced acids are not neutralized but collected as high purity products [39]. This technology is used by a company in the United States and has been tested for the degradation of HFCs in China [39].

Other technologies have been investigated for the degradation of HFCs, including the photodegradation of R-134a (GWP 1300) [49] and R-152 (GWP 16) [50] with $\mathrm{TiO}_{2}$ and UV light, and the degradation of HFCs using $\mathrm{Bi}_{2} \mathrm{O}_{3}$ as a photocatalyst under visible light irradiation [51].

\subsection{Reuse of HFCs: Circular Economy}

Despite being efficient in eliminating F-gases and fully or partially reducing their harmful effects on the environment, destruction processes may contribute to the release of GHGs. The quota systems imposed by the current F-gas legislations increased the pressure on the HFC supply chain and led to a rise in the prices of virgin refrigerants newly placed 
on the market. In this context, in some cases the reusing of valuable refrigerants recovered from EoL equipment has clear advantages over their destruction (Figure 1).

Moreover, destruction facilities are not located close to most industries and waste management facilities and do not exist in every country. Consequently, great amounts of F-gases are transported through long distances, drastically increasing costs (estimated EUR 0.10 per ton per kilometer in the EU [41]), the environmental impact (average emission value of $62 \mathrm{gCO}_{2}$ per tonne of transported cargo per $\mathrm{km} \mathrm{[52]),} \mathrm{and} \mathrm{the} \mathrm{chances} \mathrm{of} \mathrm{unintentional}$ release of the transported gases. On the contrary, it is easier and more feasible to install processing and recycling facilities close or on the same site where the F-gases are recovered (Figure 1).

A quick and cheap way of reusing refrigerants consists of cleaning-up the old refrigerant and feeding it to the same system in which it has been used before. This approach, frequently named recycling, does not guarantee that the cleaned-up refrigerant conforms to the standards of new refrigerants [41]. This may be particularly problematic in the case of complex blends, which may contain HFCs, HFOs, and other gases. In systems presenting considerable leaks, the composition of the blends can change over time due to differences in the boiling points of their constituents. Thus, the simple reutilization of the refrigerant may be problematic in terms of performance, energy use, system maintenance, and costs, due to changes in the refrigerant composition and to the presence of impurities.

A more advantageous approach is to use reclaimed refrigerants, defined by the EU as the ones that were recovered from EoL equipment and were reprocessed to meet the parameters of virgin substances, considering its intended use [23]. The reclaimed F-gases need to meet the requirements of the AHRI Standard 700 (2019) for their reuse, which are: (i) a purity of $\geq 98 \%$, (ii) presence in the vapor phase of less than $1.5 \%$ by volume (at $25{ }^{\circ} \mathrm{C}$ ) of non-condensable impurities, and (iii) presence in the liquid phase of less than $10 \mathrm{ppm}$ by weight of water, less than $0.5 \%$ by weight of all other volatile impurities, less than $0.01 \%$ by volume or weight of high boiling residue, less than 1 ppm by weight of acidity (as $\mathrm{HCl}$ ), and non-visually detectable presence of particles/solids and chloride [53].

Under the EU F-gas regulations, only virgin refrigerants (not reclaimed) that are placed on the market are included in the quotas. Thus, the utilization of reclaimed HFCs contributes to reducing the pressure on the virgin HFC supply chain, reducing the industry's dependence on costly high GWP refrigerants, and achieving the HFC phase-down goals (Figure 1). Up until now, virgin refrigerants were freely available at a low cost and therefore reusing refrigerants was not often considered. However, in the EU the first significant reduction in the quota took place in 2018 and the next one will occur in 2021. Therefore, the industry's ability to reduce, reuse, and innovate is vital for the transition to a restricted market. As HFC phase-down progresses, the utilization of reclaimed F-gases is increasing. According to the 2020 EEA report on fluorinated greenhouse gases, the reported reclaimed HFCs now make up $8 \%\left(9 \%\right.$ as $\mathrm{CO}_{2}$ eq) of the produced amount or $3 \%\left(4 \%\right.$ as $\left.\mathrm{CO}_{2} \mathrm{eq}\right)$ of the EU supply of virgin HFCs (Figure 3) [18]. While 97\% of reclaimed amounts are HFCs, $\mathrm{SF}_{6}$ contributed to about $20 \%$ (GWP) of reclaimed gas [25]. However, there is no obligation in the EU to report the reclaimed F-gases, which can make it harder to evaluate the current situation. In fact, in 2019 a strong decline in the reported reclaimed F-gases occurred, which was explained by incomplete reporting [25].

To increase the reuse rates, efforts need to be made to develop the recycling and reclamation infrastructures and to improve legislation to allow an efficient and tight control of the transport of reclaimed refrigerants. In Europe, there are already manufacturers that recover refrigerants, such as R-410A (GWP 2088), process them to virgin specifications and then sell them across Europe [54].

\subsection{New Technologies for the Recovery and Separation of HFCs}

Despite the benefits of reclaiming refrigerants at short term, at long term the switch to alternatives with lower GWP must be made. However, some of the high GWP blends currently in use are still valuable. The constituents of the most used high GWP blends, 
such as R-410A (GWP 2088) and R-404A (GWP 3922), have high value compounds that can be used as single component refrigerants or in low GWP blends.

The blend R-410A (GWP 2088) is one of the main refrigerants used in refrigeration and air conditioning systems. However, due to its high GWP, it is being substituted by alternatives with lower GWP. One of those alternatives is R-32 (GWP 677), one of the components of the blend together with R-125 (GWP 3170), mostly in low-capacity systems. This refrigerant was present in approximately 37\% of all split systems in 2019 and is expected to exceed $80 \%$ by 2023 [55]. In Japan, a complete shift towards R-32 (GWP 677) occurred in produced residential split air conditioners, starting from 2014 [56]. In some air conditioning sectors, blends of R-32 (GWP 677) with other HFCs and HFOs, such as R-454B (GWP 466) and R-452B (GWP 676), are being promoted as alternatives to R-410A (GWP 2 088).

Therefore, there are undeniable advantages in separating value-added F-gases from blends recovered from EoL equipment and further recycling and reusing them, either as single component refrigerants or in blends. However, this approach has received little encouragement and no developed technologies are currently available. Since most refrigerants are azeotropic or near-azeotropic mixtures, conventional processes, such as distillation, are not efficient or feasible. For example, R-410A (GWP 2088) is a near-azeotropic system of R-32 (GWP 677) and R-125 (GWP 3170), with an azeotropic composition at $91 \mathrm{~mol} \% \mathrm{R}-32$ (GWP 677).

The research on technologies based on environmentally benign materials that efficiently capture, separate, and recycle F-gases is vital to develop sustainable processes to reduce the environmental impact of refrigerants based on F-gases. The implementation of innovative approaches based on separation processes is vital to the functioning of a sustainable market under circular economy principles. However, few projects have been dedicated to exploring the separation of HFCs from HFC blends. Recently, under the scope of the KET4F-Gas project [57], two technologies, currently in the patent process, have been developed and prototypes have been constructed for the efficient recovery of value-added HFCs, with purity up to $99 \%$, from high-GWP refrigerant blends contained in EoL equipment, for reutilization purposes in novel environmentally friendly low-GWP blends. These technologies are easy to apply in a waste management facility due to the small space required, and due to their modularity and scalability. Moreover, these systems require low maintenance and have a long lifetime [58,59]. One of the technologies is based on adsorption processes, in which one of the components of the mixture is preferentially adsorbed into a porous material while the remaining leaves the adsorption column, including the regeneration of the adsorption column to recover the adsorbed gas [60]. The other technology is based on the separation by a membrane, in which one compound of the mixture is preferentially permeated through highly selective thin films due to differences in the size of the gas molecules and to gas-membrane interactions [61].

This example shows that innovation in the management of F-gases recovered from EoL equipment is possible and is essential to the goals of reducing the contribution of these gases to climate change. Actions, such as investment in the search for new separation technologies, need to be performed in the management of F-gases since most are recovered and destroyed at the end-of-life of the equipment, representing a loss of value-added compounds.

\section{Conclusions}

The utilization of F-gases for multiple industrial applications, such as refrigeration, air conditioning, solvents, fire extinguishing systems, and aerosols, has increased drastically in the last few decades. Despite representing a small fraction of all emitted GHGs, they contribute largely to global warming and climate change. This prompted the establishment of several international, European, and national agreements and regulations to encourage the adoption of policies and practices to mitigate their contribution to climate change. As discussed in this critical review, to achieve this objective, a multi-way strategy must be 
followed, crossing several sectors and with the responsibility of all stakeholders: policy makers, law enforcement entities, producers, industrial players, WEEE and ELV management operators, consumers, and of society in general. It is vital that the strategies consider the full F-gas scenario, including their production, use, handling and operation, disposal, destruction and recycling.

However, as discussed in this critical review, several factors may hamper the success of the developed strategies, including deficient law enforcement and activity reporting, the thriving of the black market, the lack of investment in alternative refrigerants with high efficiency and low GWP, and the adoption of inefficient or inappropriate WEEE and ELV management practices.

This critical review focused on the strategies that have been adopted to deal with the F-gases at the end of their life cycle. Despite the existence of destruction and of recycling/reclamation facilities, only a small fraction of F-gases is collected, resulting in the release of large quantities into the atmosphere. The improvement of F-gas recovery is important not only to avoid the release of these gases, but it is also an opportunity to valorize them, based on circular economy principles. F-gases are valuable materials, especially suitable for recycling and reclamation due to their high stability. Moreover, the constituents of some of the high GWP blends currently in use can be reused, after separation from the other blend constituents, as single component refrigerants or in new blends with low GWP. Thus, there is a great window of opportunity for developing new technologies based on environmentally benign materials to efficiently capture, separate, and recycle F-gases at the end of their life cycle. Some technologies have already been developed and tested, with promising results.

Funding: This work was funded by FCT/MCTES (Portugal), project PTDC/EQU-EQU /29737/2017, and was supported by the Associate Laboratory for Green Chemistry-LAQV, which is financed by national funds from FCT/MCTES (UIDB/50006/2020) and by Marine and Environmental Sciences Centre-MARE, which is financed by national funds from FCT/MCTES (UIDB/04292/2020).

Institutional Review Board Statement: Not applicable.

Informed Consent Statement: Not applicable.

Conflicts of Interest: The authors declare no conflict of interest.

\section{References}

1. Rowland, S.F. Stratospheric Ozone Depletion. Annu. Rev. Phys. Chem. 1991, 42, 731-768. [CrossRef]

2. Manzer, L.E. The CEC-Ozone Issue: Progress on the Development of Alternatives to CFCs. Science 1990, 249, 31-35. [CrossRef] [PubMed]

3. Sovacool, B.K.; Griffiths, S.; Kim, J.; Bazilian, M. Climate change and industrial F-gases: A critical and systematic review of developments, sociotechnical systems and policy options for reducing synthetic greenhouse gas emissions. Renew. Sustain. Energy Rev. 2021, 141, 110759. [CrossRef]

4. IPCC. Climate Change 2014: Mitigation of Climate Change, Contribution of Working Group III to the Fifth Assessment Report of the Intergovernmental Panel on Climate Change (IPCC); Cambridge University Press: Cambridge, UK; New York, NY, USA, 2014. Available online: https://www.ipcc.ch/site/assets/uploads/2018/02/ipcc_wg3_ar5_full.pdf (accessed on 22 March 2021).

5. European Environment Agency. EEA Greenhouse Gas-Data Viewer. Available online: https://www.eea.europa.eu/data-andmaps/data/data-viewers/greenhouse-gases-viewer (accessed on 20 November 2020).

6. Purohit, P.; Höglund-Isaksson, L. Global emissions of fluorinated greenhouse gases 2005-2050 with abatement potentials and costs. Atmos. Chem. Phys. Discuss. 2017, 17, 2795-2816. [CrossRef]

7. Öko-Recherche. Briefing Paper: Availability of Alternatives to HFCs in Commercial Refrigeration in the EU. Available online: https://www.oekorecherche.de/en/node/205 (accessed on 22 March 2021).

8. Zaelke, D.; Borgford-Parnell, N.; Andersen, S.O. Primer on HFCs Fast Action under the Montreal Protocol Can Limit Growth of Hydrofluorocarbons (HFCs), Prevent 100 to 200 Billion Tonnes of $\mathrm{CO}_{2}$-eq by 2050, and Avoid up to $0.5^{\circ} \mathrm{C}$ of Warming by 2100 . Institute for Governance \& Sustainable Development. 2018. Available online: http://www.igsd.org/wp-content/uploads/2018 /01/HFC-Primer-v11Jan18.pdf (accessed on 22 March 2021).

9. IEA. Cooling Emissions and Policy Synthesis Report. Paris. 2020. Available online: https://www.iea.org/reports/coolingemissions-and-policy-synthesis-report (accessed on 22 March 2021). 
10. World Meteorological Organization Global Ozone Research and Monitoring Project-Report No. 58. Scientific Assessment of Ozone Depletion. 2018. Available online: https://csl.noaa.gov/assessments/ozone/2018/downloads/2018OzoneAssessment.pdf (accessed on 7 May 2021).

11. Zhai, Z.J.; Helman, J.M. Climate change: Projections and implications to building energy use. Build. Simul. 2019, 12, 585-596. [CrossRef]

12. Wang, H.; Chen, Q. Impact of climate change heating and cooling energy use in buildings in the United States. Energy Build. 2014 82, 428-436. [CrossRef]

13. Wang, X.; Chen, D.; Ren, Z. Assessment of climate change impact on residential building heating and cooling energy requirement in Australia. Build. Environ. 2010, 45, 1663-1682. [CrossRef]

14. Olonscheck, M.; Holsten, A.; Kropp, J.P. Heating and cooling energy demand and related emissions of the German residential building stock under climate change. Energy Policy 2011, 39, 4795-4806. [CrossRef]

15. Dolinar, M.; Vidrih, B.; Kajfež-Bogataj, L.; Medved, S. Predicted changes in energy demands for heating and cooling due to climate change. Phys. Chem. Earth Parts A/B/C 2010, 35, 100-106. [CrossRef]

16. Jylhä, K.; Jokisalo, J.; Ruosteenoja, K.; Pilli-Sihvola, K.; Kalamees, T.; Seitola, T.; Mäkelä, H.M.; Hyvönen, R.; Laapas, M.; Drebs, A. Energy demand for the heating and cooling of residential houses in Finland in a changing climate. Energy Build. 2015, 99, 104-116. [CrossRef]

17. Park, W.Y.; Shah, N.; Gerke, B. Assessment of Commercially Available Energy-Efficient Room Air Conditioners including Models with Low Global Warming Potential (GWP) Refrigerants. Lawrence Berkeley National Laboratory. 2017. Available online: https:/ / eta-publications.lbl.gov/sites/default/files/assessment_of_racs_lbnl-_2001047.pdf (accessed on 22 March 2021).

18. Brooker, R.; Young, J.C.; Watt, A.D. Climate change and biodiversity: Impacts and policy development challenges-A European case study. Int. J. Biodivers. Sci. Ecosyst. Serv. Manag. 2007, 3, 12-30. [CrossRef]

19. Solomon, K.R.; Velders, G.J.M.; Wilson, S.R.; Madronich, S.; Longstreth, J.; Aucamp, P.J.; Bornman, J.F. Sources, fates, toxicity, and risks of trifluoroacetic acid and its salts: Relevance to substances regulated under the Montreal and Kyoto Protocols. J. Toxicol. Environ. Health Part B 2016, 19, 289-304. [CrossRef]

20. Hurwitz, M.M.; Fleming, E.L.; Newman, P.A.; Li, F.; Mlawer, E.; Cady-Pereira, K.; Bailey, R. Ozone depletion by hydrofluorocarbons. Geophys. Res. Lett. 2015, 42, 8686-8692. [CrossRef]

21. Fortems-Cheiney, A.; Saunois, M.; Pison, I.; Chevallier, F.; Bousquet, P.; Cressot, C.; Montzka, S.A.; Fraser, P.J.; Vollmer, M.K.; Simmonds, P.G.; et al. Increase in HFC-134a emissions in response to the success of the Montreal Protocol. J. Geophys. Res. Atmos. 2015, 120, 11728-11742. [CrossRef]

22. Heath, E.A. Amendment to the Montreal Protocol on Substances that Deplete the Ozone Layer (Kigali Amendment). Int. Leg. Mater. 2017, 56, 193-205. [CrossRef]

23. Regulation (EU) No 517/2014 of the European Parliament and of the Council of 16 April 2014 on Fluorinated Greenhouse Gases and Repealing Regulation (EC) No 842/2006. OJ L 150, 20.5.2014. pp. 195-230. Available online: http://data.europa.eu/eli/reg/ 2014/517/oj (accessed on 22 March 2021).

24. Regulation (EU) No 842/2006 of the European Parliament and of the Council of 17 May 2006 on Certain Fluorinated Greenhouse Gases. OJ L 161, 14.6.2006. pp. 1-11. Available online: http:/ / data.europa.eu/eli/reg/2006/842/oj (accessed on 22 March 2021).

25. EEA Report No 15/2020. Fluorinated Greenhouse Gases 2020: Data Reported by Companies on the Production, Import, Export and Destruction of Fluorinated Greenhouse Gases in the European Union, 2007-2019. 2020. Available online: https: / / www.eea.europa.eu/publications / fluorinated-greenhouse-gases-2020 (accessed on 22 March 2021).

26. EIA. Doors Wide Open: Europe's Flourishing Illegal Trade in Hydrofluorocarbons (HFCs). 2019. Available online: https: / / eia-international.org/wp-content/uploads/EIA-report-Doors-wide-open.pdf (accessed on 22 March 2021).

27. Clarke, L.; Eom, J.; Marten, E.H.; Horowitz, R.; Kyle, P.; Link, R.; Mignone, B.K.; Mundra, A.; Zhou, Y. Effects of long-term climate change on global building energy expenditures. Energy Econ. 2018, 72, 667-677. [CrossRef]

28. Verichev, K.; Zamorano, M.; Carpio, M. Effects of climate change on variations in climatic zones and heating energy consumption of residential buildings in the southern Chile. Energy Build. 2020, 215, 109874. [CrossRef]

29. Verichev, K.; Zamorano, M.; Carpio, M. Assessing the applicability of various climatic zoning methods for building construction: Case study from the extreme southern part of Chile. Build. Environ. 2019, 160, 106165. [CrossRef]

30. Heredia-Aricapa, Y.; Belman-Flores, J.; Mota-Babiloni, A.; Serrano-Arellano, J.; García-Pabón, J.J. Overview of low GWP mixtures for the replacement of HFC refrigerants: R134a, R404A and R410A. Int. J. Refrig. 2020, 111, 113-123. [CrossRef]

31. Aprea, C.; Greco, A.; Maiorino, A. An experimental investigation on the substitution of HFC134a with HFO1234YF in a domestic refrigerator. Appl. Therm. Eng. 2016, 106, 959-967. [CrossRef]

32. Belman-Flores, J.; Rangel-Hernández, V.; Usón, S.; Rubio-Maya, C. Energy and exergy analysis of R1234yf as drop-in replacement for R134a in a domestic refrigeration system. Energy 2017, 132, 116-125. [CrossRef]

33. Golzari, S.; Kasaeian, A.; Daviran, S.; Mahian, O.; Wongwises, S.; Sahin, A.Z. Second law analysis of an automotive air conditioning system using HFO-1234yf, an environmentally friendly refrigerant. Int. J. Refrig. 2017, 73, 134-143. [CrossRef]

34. Gullo, P.; Cortella, G. Theoretical evaluation of supermarket refrigeration systems using R1234ze(E) as an alternative to high-global warming potential refrigerants. Sci. Technol. Built Environ. 2016, 22, 1145-1155. [CrossRef] 
35. ZERO: Mais de 90\% Dos Gases de Refrigeração de Frigoríficos e Equipamentos de ar Condicionado São Libertados Para a at-Mosfera. Available online: https:/ / zero.ong/mais-de-90-dos-gases-de-refrigeracao-de-frigorificos-e-equipamentos-de-arcondicionado-sao-libertados-para-a-atmosfera/ (accessed on 22 March 2021).

36. Directive 2000/53/EC of the European Parliament and of the Council of 18 September 2000 on End-of Life Vehicles-Commission Statements OJ L 269, 21.10.2000. pp. 34-43. Available online: http:/ / data.europa.eu/eli/dir/2000/53/oj (accessed on 18 April 2021).

37. Directive 2006/40/EC of the European Parliament and of the Council of 17 May 2006 Relating to Emissions from Air Conditioning Systems in Motor Vehicles and Amending Council Directive 70/156/EEC (Text with EEA Relevance) OJ L 161, 14.6.2006. pp. 12-18. Available online: http:/ / data.europa.eu/eli/dir/2006/40/oj (accessed on 18 April 2021).

38. ICF International. Analysis on the Recovery of Fluorinated Greenhouse Gases in EU-27 in the Period of 2004-2007 and De-termination of Options for Further Progress. Prepared for the European Commission. October 2008. Available online: https:/ / ec.europa.eu/clima/sites/clima/files/f-gas/docs/gas_recovery_report_en.pdf (accessed on 29 March 2021).

39. 2018 TEAP Report, Volume 2: Decision XXIX/4 TEAP Task Force Report on Destruction Technologies for Controlled Sub-stances. Available online: https:/ / ozone.unep.org/sites/default/files/2019-04/TEAP-DecXXIX4-TF-Report-April2018.pdf (accessed on 29 March 2021).

40. European Environment Agency. Briefing: Ozone Depleting Substances 2020. Available online: https://www.eea.europa.eu/ themes/climate/ozone-depleting-substances-and-climate-change/2020 (accessed on 22 March 2021).

41. ICF International. Report Prepared for the European Commission. Identifying and Assessing Policy Options for Promoting the Recovery and Destruction of Ozone Depleting Substances (ODS) and Certain Fluorinated Greenhouse Gases (F-Gases) Banked In Products and Equipment. May 2010. Available online: https://ec.europa.eu/clima/sites/clima/files/ozone/docs/ods_f-gas_ destruction_report_en.pdf (accessed on 22 March 2021).

42. Technology and Economic Assessment Panel (TEAP). Report of the UNEP Technology and Economic Assessment Panel (TEAP), Report of the Task Force on Destruction Technologies. Montreal Protocol on Substances That Deplete the Ozone Layer. United Nations Environment Programme. Volume 3B. April 2002. Available online: https://ozone.unep.org/sites/default/files/2019-0 5/TEAP02V3b\%20\%281\%29.pdf (accessed on 22 March 2021).

43. Stanley, K.M.; Say, D.; Mühle, J.; Harth, C.M.; Krummel, P.B.; Young, D.; O’Doherty, S.J.; Salameh, P.K.; Simmonds, P.G.; Weiss, R.F.; et al. Increase in global emissions of HFC-23 despite near-total expected reductions. Nat. Commun. 2020, 11, 1-6. [CrossRef]

44. Tsang, W.; Burgess, D.R.; Babushok, V. On the Incinerability of Highly Fluorinated Organic Compounds. Combust. Sci. Technol. 1998, 139, 385-402. [CrossRef]

45. Roh, S.A.; Kim, W.H.; Jung, D.S.; Hong, B.K. Thermal destruction of HFC-134a in pilot-, and full-scale gasification systems. J. Energy Inst. 2019, 92, 1842-1851. [CrossRef]

46. Jasiński, M.; Dors, M.; Mizeraczyk, J.; Jasiński, M. Destruction of Freon HFC-134a Using a Nozzleless Microwave Plasma Source. Plasma Chem. Plasma Process. 2009, 29, 363-372. [CrossRef]

47. Watanabe, T.; Tsuru, T. Water plasma generation under atmospheric pressure for HFC destruction. Thin Solid Film. 2008, 516, 4391-4396. [CrossRef]

48. Mok, Y.S.; Demidyuk, V.; Whitehead, J.C. Decomposition of Hydrofluorocarbons in a Dielectric-Packed Plasma Reactor. J. Phys. Chem. A 2008, 112, 6586-6591. [CrossRef] [PubMed]

49. Delprat, H. Air Purification by Heterogeneous Photocatalysis. Application to the Treatment of a Confined Atmosphere Polluted by Freons or Pyrazines. Ph.D. Thesis, Lyon's I University, Lyon, France, 1996.

50. Sangchakr, B.; Hisanaga, T.; Tanaka, K. Photocatalytic degradation of 1,1-difluoroethane (HFC-152a). Chemosphere 1998, 36, 1985-1992. [CrossRef]

51. Yin, L.F. Photocatalytic Degradation of Hydrofluorocarbon under Visible Light Irradiation. Appl. Mech. Mater. 2014, 651-653, 1357-1360. [CrossRef]

52. ECTA. Guidelines for Measuring and Managing CO2 Emission from Freight Transport Operations. March 2011. Available online: https:/ / www.ecta.com/resources/Documents/Best\%20Practices\%20Guidelines/guideline_for_measuring_and_managing_ co2.pdf (accessed on 29 March 2021).

53. AHRI Standard 700. 2019 Standard for Specifications for Refrigerants. Available online: https://www.ahrinet.org/App_Content/ ahri/files/STANDARDS/AHRI/AHRI_Standard_700_2019.pdf (accessed on 29 March 2021).

54. DAIKIN. Closing the Loop: Towards a Circular Economy for Refrigerants. Available online: https:/ /www.daikin.eu/en_us/ daikin-blog/building-a-circular-economy.html (accessed on 29 March 2021).

55. BSRIA. BSRIA's View on Refrigerant Trends in AC and Heat Pump Segments. Available online: https://www.bsria.com/uk/ news/article/bsrias_view_on_refrigerant_trends_in_ac_and_heat_pump_segments/ (accessed on 22 March 2021).

56. EFCTC. Energy Efficient Air-Conditioning. Available online: https://www.fluorocarbons.org/applications/energy-efficient-airconditioning/ (accessed on 22 March 2021).

57. KET4F-Gas. Available online: http:/ / www.ket4f-gas.eu/ (accessed on 29 March 2021).

58. KET4F-Gas: Good Practices Handbook for Industry and Waste Managers. Available online: http://www.ket4f-gas.eu/wpcontent/uploads/2021/03/EN_Good_practices.pdf (accessed on 29 March 2021). 
59. KET4F-Gas: Roadmap for the Public Administrations in Charge of Waste Management. Available online: http://www.ket4f-gas. eu/wp-content/uploads/2021/03/EN_Roadmap.pdf (accessed on 29 March 2021).

60. Sosa, J.E.; Malheiro, C.; Ribeiro, R.P.P.; Castro, P.J.; Piñeiro, M.M.; Araújo, J.M.M.; Plantier, F.; Mota, J.P.B.; Pereiro, A.B. Adsorption of fluorinated greenhouse gases on activated carbons: Evaluation of their potential for gas separation. J. Chem. Technol. Biotechnol. 2020, 95, 1892-1905. [CrossRef]

61. Pardo, F.; Zarca, G.; Urtiaga, A. Separation of Refrigerant Gas Mixtures Containing R32, R134a, and R1234yf through Poly(etherblock-amide) Membranes. ACS Sustain. Chem. Eng. 2020, 8, 2548-2556. [CrossRef] 